\title{
Paper Impact of Structures on the Operation of Air Traffic Radiolocation and Radionavigation Surveillance Systems
}

\author{
Maciej J. Grzybkowski, Daniel Niewiadomski, and Marcin Mora \\ National Institute of Telecommunications, Warsaw, Poland
}

https://doi.org/10.26636/jtit.2021.155221

\begin{abstract}
The article describes interference affecting the operation of radiolocation and radionavigation devices used in the air traffic surveillance systems, caused by the proximity of building structures. The impact of a hypothetical structure on the operation of primary and secondary air traffic surveillance radars and DVOR/DME beacons was simulated. The results of this simulation are presented in the form of airspace sectors in which false identification of aircraft may occur, and where it will not be possible to identify aircraft or use beacons due to the certain portion of airspace being in the shadow created by the structure. Analysis of the possibility of the PSR radar receiver being blocked by a strong signal reflected from a nearby building was performed as well.
\end{abstract}

Keywords-air traffic safety, environment obstacles, ground radiolocalization systems.

\section{Introduction}

Civilian (and military) aviation authorities aim to ensure the safety of personnel and passengers traveling by air. The desired level of safety is ensured by complying with organizational rules and meeting applicable technical requirements. Ground-based air traffic surveillance systems are an important aspect of technical flight safety measures. Air traffic control systems monitor aircraft traveling enroute, during the departure and approach phase of the flight (around airports) and at airports themselves. Air traffic surveillance is performed with the use of various radio-electronic solutions, such as radionavigation, radiolocation and air radiocommunication systems. Ground-based air traffic surveillance hardware is usually located at airport premises, near the runways, but may be also positioned at other locations of key significance for air traffic control. Such hardware interacts with devices installed aboard the aircraft.

Terrestrial radionavigation systems ecomprise, inter alia, non-directional beacons (NDB), distance measuring equipment (DME), VHF Omni Directional Range (VOR), and VOR using the Doppler effect (DVOR) azimuth beacons, markers (route beacons) and Instrument Landing System(s) (ILS) - solutions made up of directional beacons that assist crews while landing in low visibility conditions, or their microwave versions, known as Microwave Landing System
(MLS). Ground-based radiolocation systems use radars to indicate the position of the aircraft in airspace, they are primary surveillance radars (PSRs), and to identify of aircraft and provide much more information on it, they are secondary surveillance radars (SSRs) [1].

Correct operation of air traffic surveillance systems is crucial and their performance should not be affected by any potential disturbances. The sources of such disturbances may include electromagnetic (active) sources, or emission caused by environmental conditions (passive). Specifications protecting radionavigation and radiolocation systems against interference originating from various sources are provided for in numerous documents published, for instance, by the International Telecommunications Union [2]-[6]. However, disturbance affecting the operation of ground-based air traffic surveillance devices, caused by closely located structures, including various types of buildings, is a problem as well. In some publications, e.g. [7]-[9], the authors noted the potential impact that man-made obstacles, such as buildings, may exert on the operation of radars. However, they failed to present any methods for analyzing the outcomes of such impact.

Structures present in close proximity of navigation systems need to be positioned in a manner allowing to minimize their negative impact. Some typical types of interference include electromagnetic wave reflections and shadowing effects rendering specific portions of airspace unsuitable for monitoring. Therefore, restrictions concerning the height of buildings existing in close proximity to these radio devices are introduced. As it is impossible to do away with all structures in the vicinity of the abovementioned devices (e.g. airport terminals, hangars, air traffic control towers, or even offices and hotels), it is recommended that their impact on the operation of such systems be studied in order to gather information about the potential adverse types of impact.

This article covers the effects of passive impact that structures may exert on the operation of air traffic surveillance systems. A scenario in which fictitious structures impact the operation of hypothetical radiolocation devices located within the airport perimeter will be simulated as well, and an analysis of the effects of such impact will be performed. 
In the literature, e.g. in [10]-[12], theoretical considerations related to reflections of waves generated by SSR radars, caused by ground-based objects, as well as to the scattering of radio waves by wind turbines may be found. However, it is the practical effects of these reflections, as well as the outcomes of radio wave scattering and shadowing phenomena that are extremely important and interesting for the aviation authorities.

\section{Effects of Disturbance Affecting Air Traffic Surveillance Systems}

False aircraft locations caused by the reflection of electromagnetic waves are one of the most serious effects of disturbance created by structures present in the vicinity of terrestrial radionavigation or radiolocation equipment. In addition to such false locations, coordinate- and altituderelated errors in determining the azimuth of and the distance to beacons may be experienced as well. These phenomena are caused by the multi-path propagation of the radio wave in scenarios in which other objects (structures), reflecting the emitted signals are located in the vicinity of the tracking facilities or the tracked object.

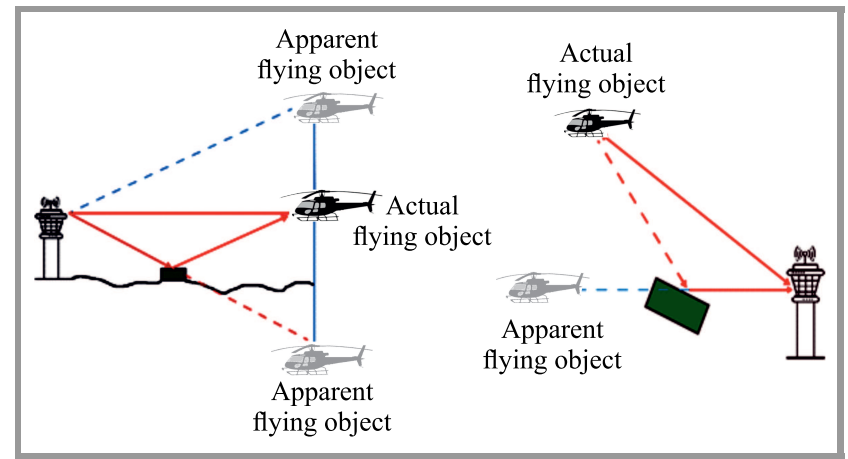

Fig. 1. False location of a flying object identified when the radio wave is reflected by a building [1].

Such cases are illustrated in Fig. 1. Radio shadowing caused by structures is another adverse effect. In this scenario, certain space exists that cannot be reached by radio waves emitted from the transmitters of radiolocation devices, as it is located below the line of sight. The radio shadowing phenomenon is somewhat alleviated by tropospheric refraction curving the trajectory of radio waves. Antennas of radiolocation and radio navigation devices are designed in such a way that their vertical radiation pattern covers a large range of elevation angles in relation to the Earth's surface, i.e. both small angles for low-flying and distant aircraft and large angles for aircraft flying high and close to the antenna. However, the resulting radio shadowing effect limits radar or beacon coverage, as radio waves fail to reach flying objects located in a certain part of the airspace. On the other hand, from the point of view of aircraft, objects located in the proximity of ground-based radio navigation systems weaken their signals which cannot be received, in some cases, by planes. Due to high operating frequency used, the diffraction of radio waves observed at the edges of buildings is small, but the radio wave is almost completely suppressed in the radio shadow zone. Therefore, obstruction zones are defined, in radiolocation, both in terms of their horizontal and vertical planes. These sectors are the portions of airspace in which aircraft are undetectable or where ground equipment is undetectable by aircraft.

Contact with ground-based radiolocation systems may also be lost due to radar receiver blocking (saturation). This may be the case in a situation in which a high-power radar pulse is generated and directed towards objects located nearby. The signal reflected by these objects returns into the aperture of the radar antenna. Because of the high power of the reflected pulse signal, a short break in the receiver's operation may occur due to the saturation of its front-end circuit. This phenomenon is quite short-lasting due to the duration of the reflected signal pulse and the rotation speed of the radar antenna. But even such short breaks in the operation of the receiver make it impossible to distinguish objects located further away, thus temporarily preventing objects positioned at greater distances from being identified. The receiver blocking phenomenon applies only to PSR radars in which the emission and reception of pulsed signals occurs at the same frequency. SSR radar receivers are not blocked by reflections from nearby objects, as they operate based on a different principle. Such radars use two different frequencies for transmitting and receiving.

To avoid blocking a PSR radar, the power of the signal arriving at its receiver, after being reflected from a (nearby) structure $P_{o}$, should be lower than the receiver's saturation power $P_{b l}$.

$$
P_{o} \leq P_{b l}
$$

$P_{o}$ may be determined by:

$$
P_{o}=P_{p r}+G_{r}\left(\Theta_{r}\right)-L_{b}-L_{f o}+M-R[\mathrm{dBm}],
$$

where:

$P_{p r}$ - equivalent power radiated by the radar isotropically (in a pulse) $[\mathrm{dBm}]$,

$G_{r}\left(\Theta_{r}\right)$ - energy gain of the receiving antenna in relation to the isotropic antenna $[\mathrm{dBi}]$,

$\Theta_{r}$ - antenna elevation angle considering the slope of the antenna pattern,

$L_{b}$ - attenuation of the radio path on the incident wave and reflected from the object towards the antenna $[\mathrm{dB}]$,

$L_{f o}-$ receiver feeder attenuation $[\mathrm{dB}]$,

$M-$ margin factor considering multipath propagation $[\mathrm{dB}]$, $R$ - object reflection coefficient $[\mathrm{dB}]$.

In most cases, the $M$ factor may be left out because the receiver is always blocked when the reflecting objects are very close to the radar (are located in the near field zone). Therefore, it is assumed that the object from which the radio wave is reflected, being capable of blocking the receiver, is not located in the near field zone of the PSR radar antenna. The worst conditions for blocking the radar receiver occur when waves propagate in free space, without scattering, atmospheric absorption and when the object's reflection 
coefficient equals $0 \mathrm{~dB}$. When needed, different reflection coefficient values for various frequencies and wave polarizations, as well as for different types of building materials may be calculated according to the methodology presented in [13].

It should be emphasized that modern PSR radars are equipped with a sensitivity time control (STC) device used to suppress strong signals generated by reflections at very short distances. Nevertheless, any structure present in close proximity to the radar may reflect radio waves. Hence, an analysis of a scenario in which the receiver may be potentially blocked by reflections should always be performed.

\section{Simulation of Interferences Caused by Structures}

Simulations determining the impact of nearby buildings on the operation of ground air traffic control devices should allow to designate radio-limited zones. When designing structures present in the vicinity of radiolocation devices, such an analysis should be carried out in order to obtain information about potentially incorrect operation of equipment. In order to assess spatial limitations of radar (loss of coverage along a specific direction and at a specific height above ground level) caused by the formation of radio shadow zones, the solid of the planned structure should be modeled as a terrain obstacle. Next, the elevation angles and azimuths of the beam radiated by the radar incident on the analyzed structure should be determined. Such a procedure allows to identify areas in which radio shadows caused by this structure are formed, i.e. areas in which radio visibility is reduced. Similarly, areas with reflections that may result in false aircraft locations being determined may be identified.

In order to simulate disturbances affecting the operation of radiolocation devices and caused by ground structures, a fictitious building, i.e. hotel complex, was modeled in the vicinity of one of the inactive airports in Lower Silesia, Poland. Fictitious PSR and SSR radars, as well as DVOR/DME beacons, were modeled, too. Their layout is shown in Fig. 2. Calculations related to airspace zones in

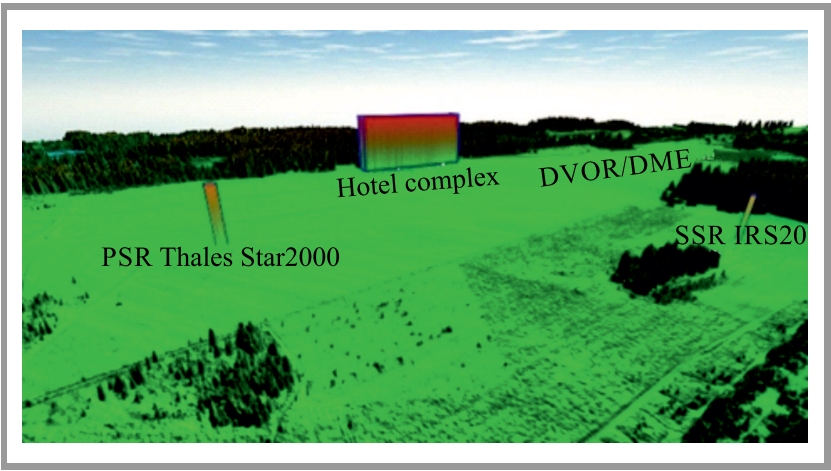

Fig. 2. Ground-based aviation equipment and hotel buildings modeled on the DTM map base. which radio shadows may appear and in which locations of aircraft may be determined falsely relied upon a detailed digital map (digital terrain model - DTM).

Tables 1-3 present selected basic parameters of typical PSR and SSR radars, as well as of DVOR/DME beacons used for the purpose of the simulation described in this article.

Table 1

Selected basic parameters of a PSR radar

\begin{tabular}{|c|c|}
\hline Operating frequency [MHz] & 2800 \\
\hline Mechanical antenna tilt [ $\left.{ }^{\circ}\right]$ & 0 \\
\hline Antenna gain - high beam [dBi] & 32 \\
\hline Antenna gain - low beam [dBi] & 33 \\
\hline Pulse radiation power [kW] & 32 \\
\hline $\begin{array}{c}\text { Height of the electrical center } \\
\text { of the antenna [m] a.g.l. }\end{array}$ & 37 \\
\hline
\end{tabular}

Table 2

Selected basic parameters of the SSR radar

\begin{tabular}{|c|c|}
\hline Operating frequency [MHz] & $1030 / 1090$ \\
\hline Mechanical antenna tilt $\left[^{\circ}\right]$ & 0 \\
\hline $\begin{array}{c}\text { Height of the electrical center } \\
\text { of the antenna [m] a.g.l. }\end{array}$ & 30 \\
\hline
\end{tabular}

Table 3

Selected basic parameters of the DVOR/DME

\begin{tabular}{|c|c|}
\hline Type of DVOR antenna & Alford slot antenna \\
\hline Type of DME antenna & Omnidirectional \\
\hline $\begin{array}{c}\text { Height of the electrical center } \\
\text { of the DVOR antenna [m] a.g.l. }\end{array}$ & 4.7 \\
\hline $\begin{array}{c}\text { Height of the electrical center } \\
\text { of the DME antenna [m] a.g.l. }\end{array}$ & 8 \\
\hline
\end{tabular}

\subsection{Simulation of the Shape of the Radio Shadow Zone Caused by Hotel Buildings}

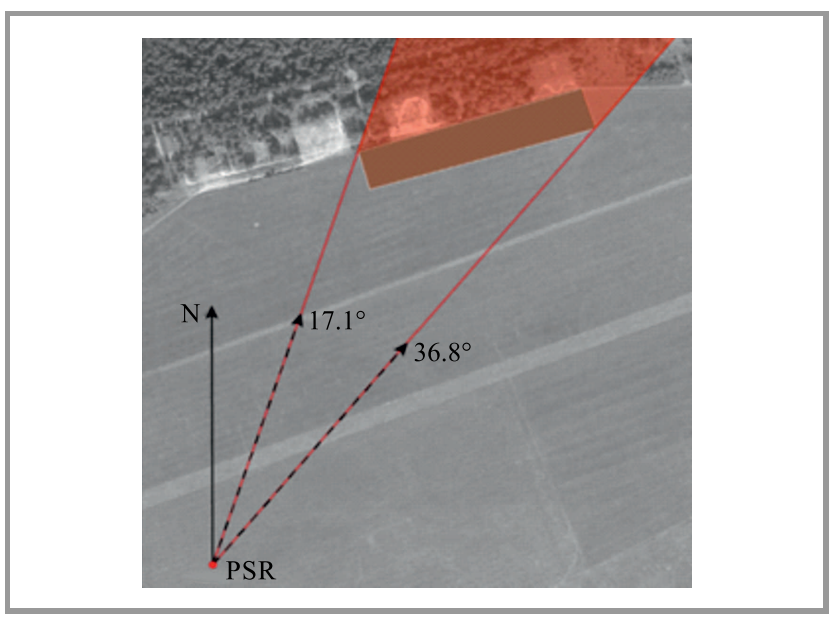

Fig. 3. Azimuth range in which the horizontal diaphragm/radio shadowing will occur for PSR radar. 


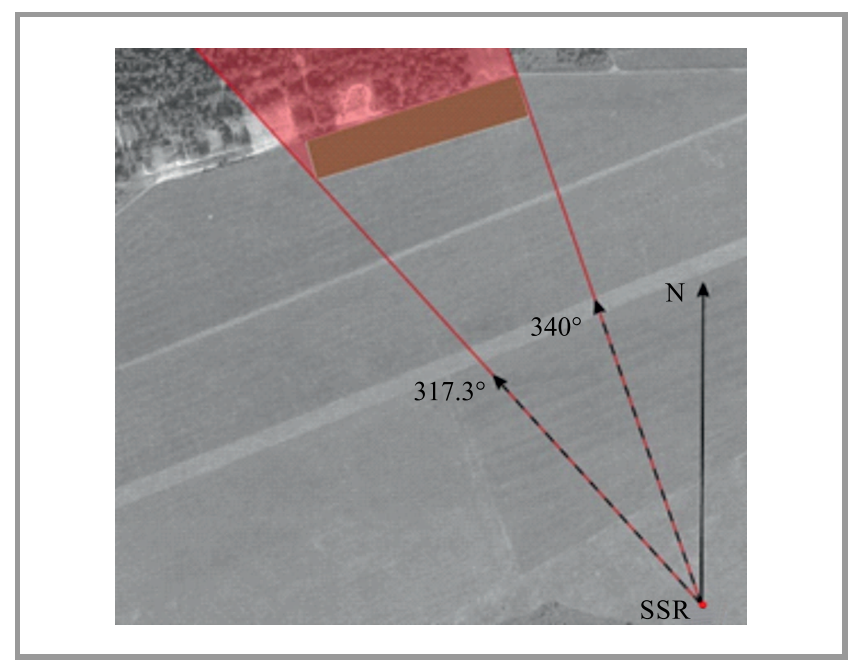

Fig. 4. Azimuth range in which the horizontal diaphragm/radio shadowing will occur for SSR radar.

By simulating the building's impact on the operation of PSR and SSR radars, a radio shadow zone, horizontal and vertical diaphragms of PSR and SSR radars, as well as areas with potential range losses could be determined. Figures 3 and 4 show the calculated azimuth ranges with the horizontal diaphragm of PSR and SSR radars.

Figures 5 and 6 show the calculated azimuth ranges in which the vertical diaphragm of PSR and SSR radars will occur. The following designators are used in these drawings:

- $\Phi$ - angle of deviation from the direction of the maximum radiation,

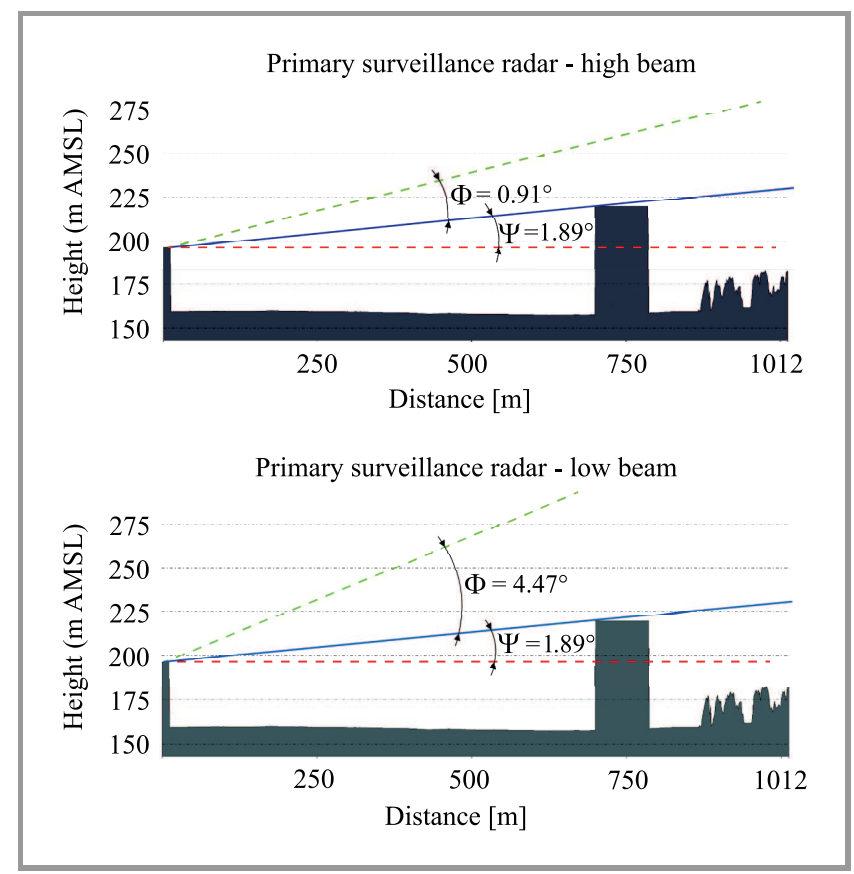

Fig. 5. Azimuth range in which the vertical diaphragm/radio shadowing will occur for PSR radar. (see the digital edition for color images)

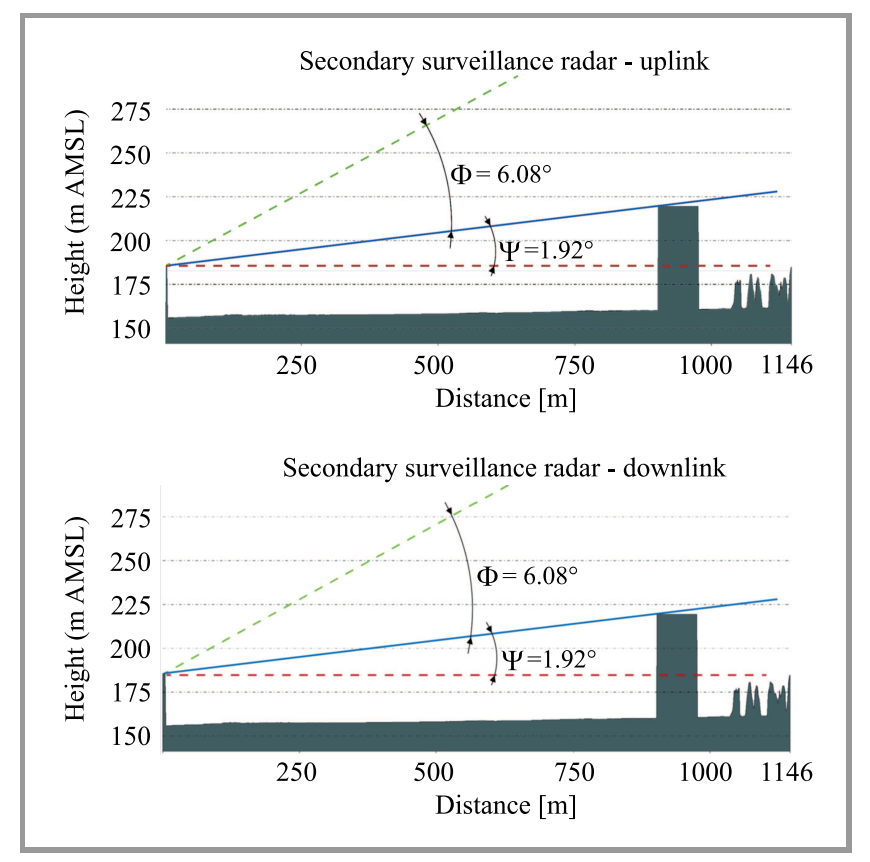

Fig. 6. Azimuth range in which the vertical diaphragm/radio shadowing will occur for SSR radar.

- $\Psi$ - angle of the building's facade,

- dashed red line - height of the electrical center of the antenna above ground level,

- dashed green line - direction of maximum radiation,

- solid blue line - radar antenna's direct line of sight.

Using the radiation characteristics of the radar antenna system, the areas of the airspace (with height being a function of distance) in which radar coverage is lost have been determined. These areas were designated for both PSR radiation beams, i.e. for the upper and lower beam, and for the SSR radar radiation beams serving the downlink and uplink.

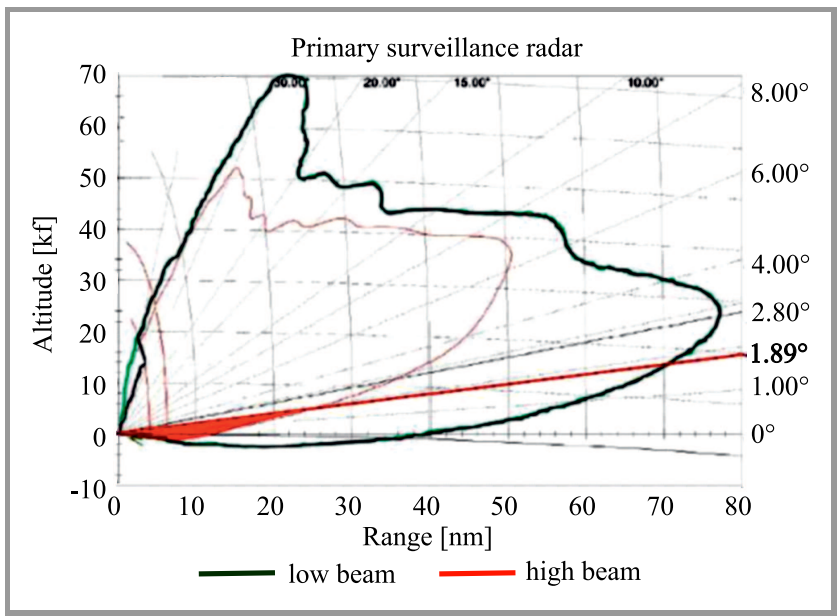

Fig. 7. The area (marked red) in which PSR radar coverage is lost due to the screening effect caused by the hotel building (radar high beam). 


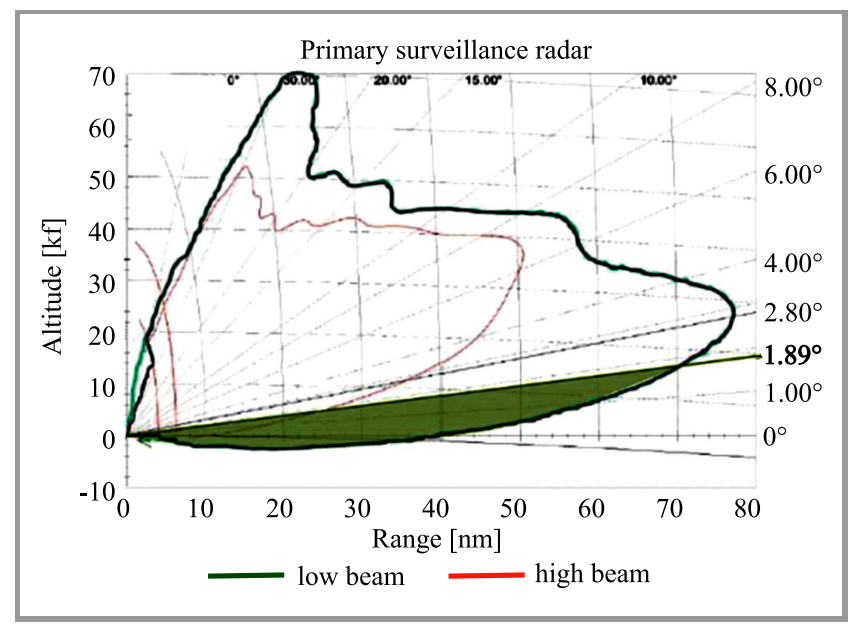

Fig. 8. The area (marked green) in which PSR radar coverage is lost due to the screening effect caused by the hotel building (radar high beam).

Figures 7 and 8 show the area with PSR radar coverage lost, while Figs. 9 and 10 show the area with SSR radar coverage lost.

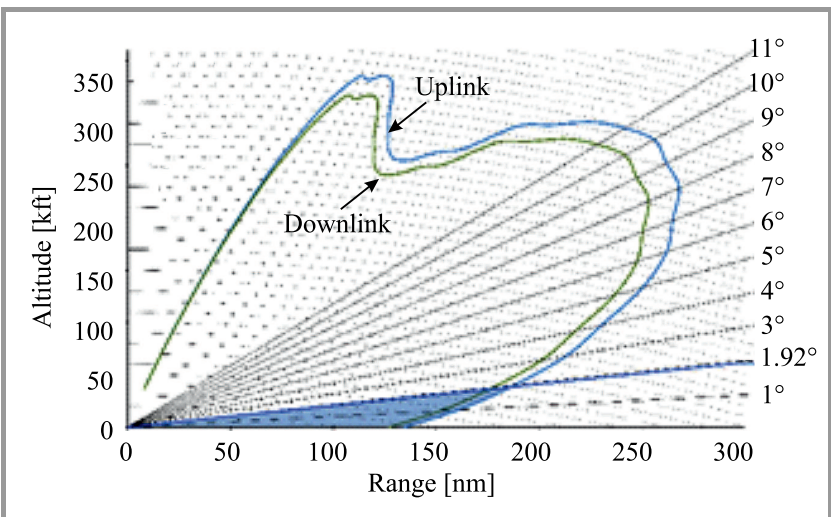

Fig. 9. The area (marked blue) in which SSR radar coverage is lost due to the screening effect caused by the hotel building (beam serving the uplink).

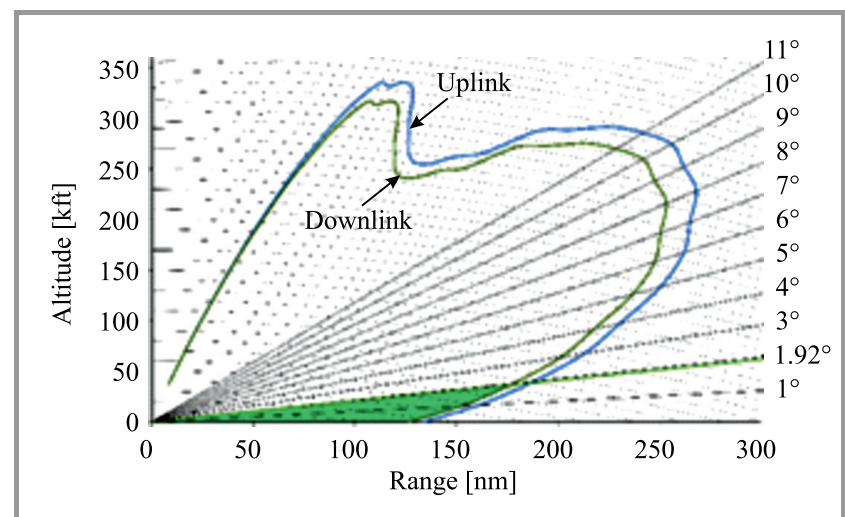

Fig. 10. The area (marked green) in which the SSR radar coverage is lost due to the screening effect caused by the hotel building (beam serving the downlink).
Table 4 presents the boundaries of the space in which loss of the PSR radar coverage is expected (with height above ground level being a function of distance), occurring within the azimuth range of $17.1-36.8^{\circ}$.

Table 4

Loss of PSR radar coverage

\begin{tabular}{|c|c|c|c|c|}
\hline \multirow{2}{*}{ High beam } & $\begin{array}{c}\text { Radar operating range } \\
\text { [nautical miles] }\end{array}$ & 10 & 15 & 20 \\
\cline { 2 - 5 } & $\begin{array}{c}\text { Radar operating ceiling } \\
\text { [thousands of feet] }\end{array}$ & 0.2 & 0.3 & 0.4 \\
\hline \multirow{2}{*}{ Low beam } & $\begin{array}{c}\text { Radar operating range } \\
\text { [nautical miles] }\end{array}$ & 20 & 40 & 70 \\
\cline { 2 - 5 } & $\begin{array}{c}\text { Radar operating ceiling } \\
\text { [thousands of feet] }\end{array}$ & 0.4 & 0.8 & 1.6 \\
\hline
\end{tabular}

Table 5 shows the boundaries of the space in which loss of the SSR radar coverage is expected (with height above ground level being a function of distance), occurring within the azimuth range of $317.3-340^{\circ}$.

Table 5

Area with PSR radar coverage lost

\begin{tabular}{|c|c|c|c|c|}
\hline \multirow{2}{*}{$\begin{array}{c}\text { Uplink } \\
\text { beam }\end{array}$} & $\begin{array}{c}\text { Radio operating range } \\
\text { [nautical miles] }\end{array}$ & 50 & 100 & 180 \\
\cline { 2 - 5 } & $\begin{array}{c}\text { Radar operating ceiling } \\
\text { [thousands of feet] }\end{array}$ & 13 & 30 & 70 \\
\hline \multirow{2}{*}{$\begin{array}{c}\text { Downlink } \\
\text { beam }\end{array}$} & $\begin{array}{c}\text { Radar operating range } \\
\text { [nautical miles] }\end{array}$ & 50 & 100 & 180 \\
\cline { 2 - 5 } & $\begin{array}{c}\text { Radar operating ceiling } \\
\text { [thousands of feet] }\end{array}$ & 12 & 30 & 60 \\
\hline
\end{tabular}

\subsection{Identification of Zones with Potential False Detection of Flying Objects}

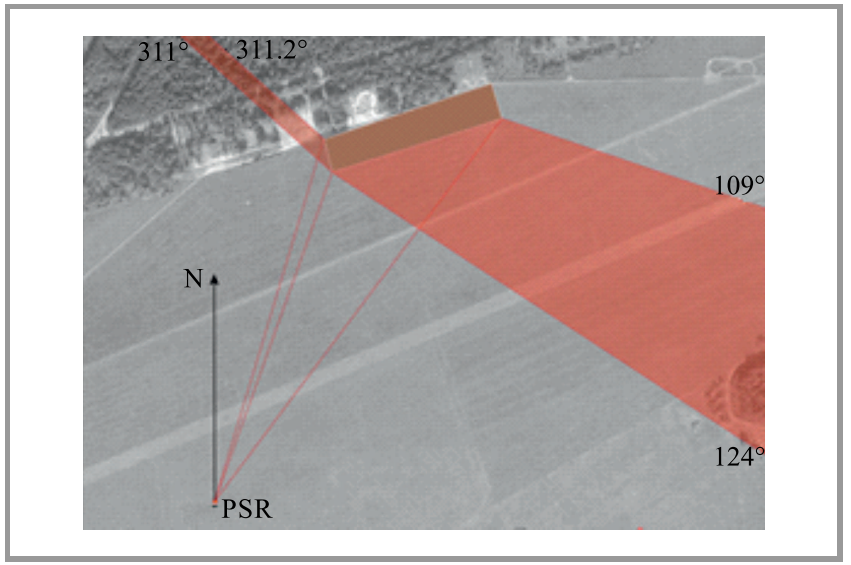

Fig. 11. Calculated azimuths at which primary radar beam will reflect from the hotel buildings in the horizontal plane. 


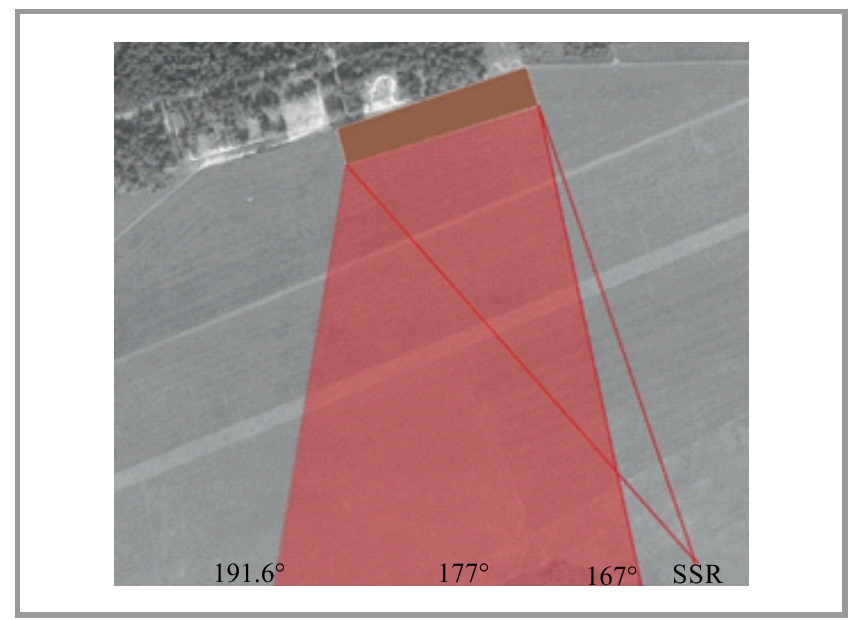

Fig. 12. Calculated azimuths values at which secondary radar beam will reflect from the hotel buildings in the horizontal plane.

In the scenario in which radar beams may be reflected by the hotel buildings, thus leading to false determination of the position of flying objects, calculations of horizontal and vertical plane azimuth ranges were performed. Figures 11 and 12 show the ranges of radar beam reflections from hotel buildings in the horizontal plane, for PSR and SSR radars. In the case of primary radar, a location error may occur in the azimuth ranges of $109-124^{\circ}$ and $311-311.2^{\circ}$.

For secondary radar, incorrect detection due to radar beam may occur in the azimuth range of $167-191.6^{\circ}$.

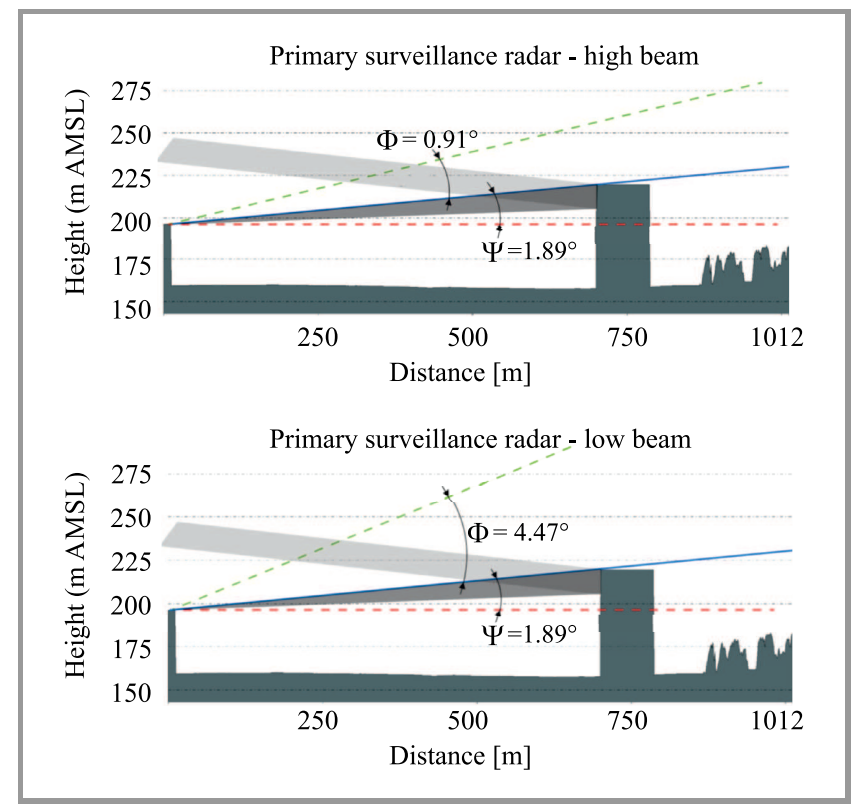

Fig. 13. Calculated azimuth range at which primary radar beam will reflect from the hotel buildings in the vertical plane.

Figures 13 and 14 show the range of radar beam reflections from hotel buildings in the vertical plane, for PSR and SSR radar, respectively. The markings of angles and lines are the same as in Figs. 5 and 6.

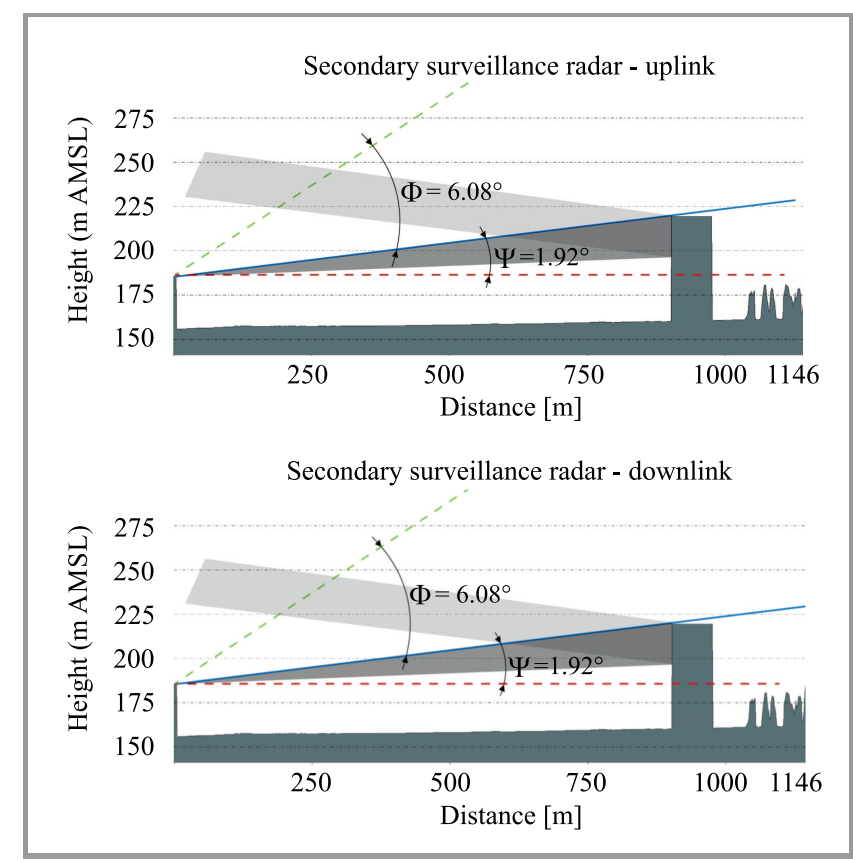

Fig. 14. Calculated azimuth range at which secondary radar beam will reflect from the hotel buildings in the vertical plane.

\subsection{Simulation of Disturbances Affecting the Operation of DVOR/DME Beacons}

When considering limitations affecting the operation of a beacon, an analysis of its location in relation to buildings should be performed in order to determine the form of the diaphragm/radio shadowing. It causes loss of the beacon's operating range. Apart from being diffracted at the edges of the structure, it was assumed that the radio wave is completely suppressed in the shadow zone, making it impossible to identify the beacon of flying objects. In addition, it is necessary to establish the boundaries of the airspace in which false detections of the beacon's position may take place due to reflections from the walls of the building.

Results of analyses concerned with the existence of the radio shadowing zone are presented in the Figs. 15-16. Figure 15 shows the determined loss of operating range of

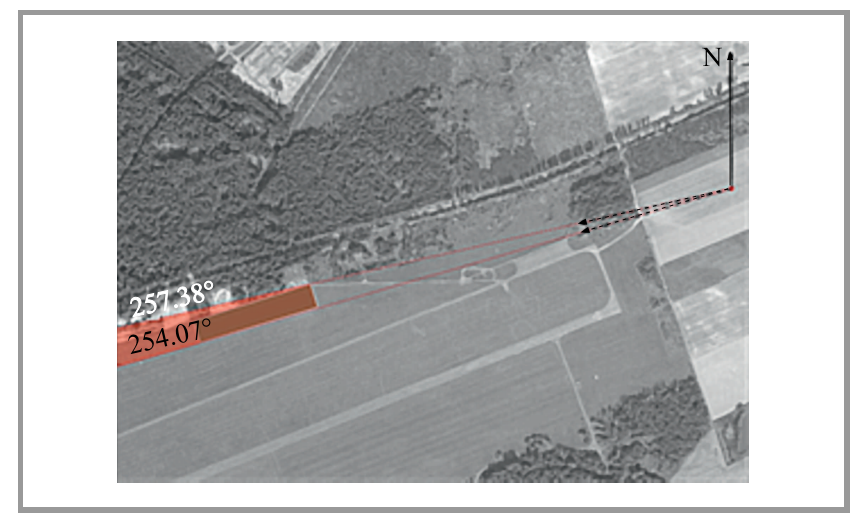

Fig. 15. Calculated azimuths range at which the horizontal diaphragm of DVOR/DME beacons will occur. 
DVOR/DME beacons due to the diaphragm/radio shadowing caused by the hotel buildings in the horizontal plane. The loss of beacon's range (no identification possible) may occur within the azimuth range of 254.07-257.38 .

Figure 16 shows the determined loss of operating range of DVOR/DME beacons due to the diaphragm/radio shadowing caused by the hotel buildings in the vertical plane.

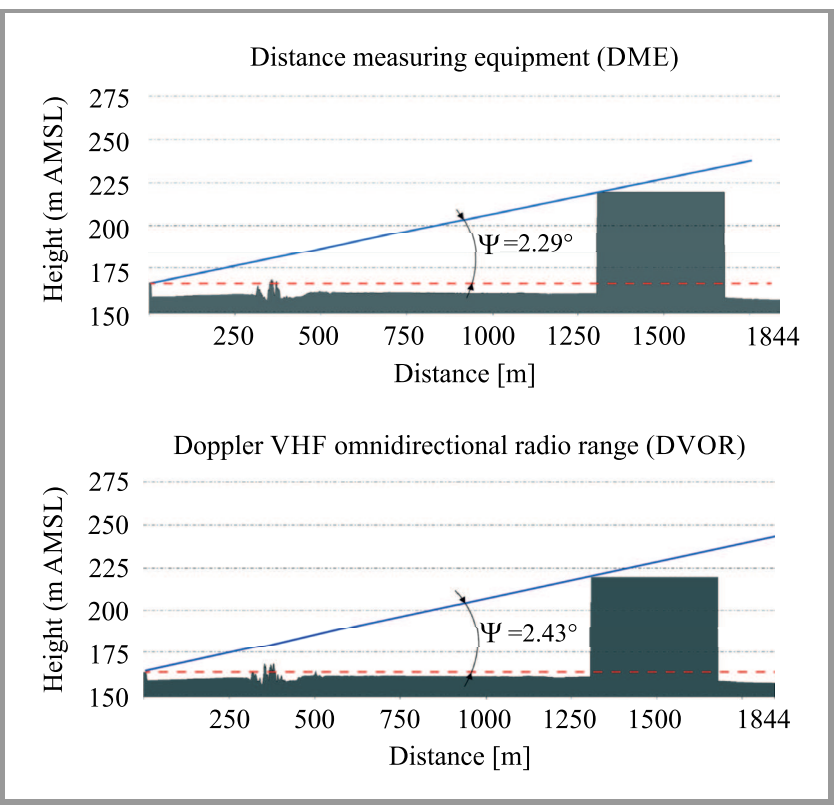

Fig. 16. Vertical azimuths below which signals of DVOR/DME beacons are obscured.

It was determined that in this case the loss of the ability to identify the beacon in the vertical plane, due radio shadowing, will be experienced below the elevation angle of $2.29^{\circ}$ and for $2.43^{\circ}$ for DME and DVOR, respectively.

Results of the analysis allowing to delineate the portion of the airspace in which flying objects may erroneously determine the location of beacons due to the reflections from the building, are shown in Figs. 17 and 18.

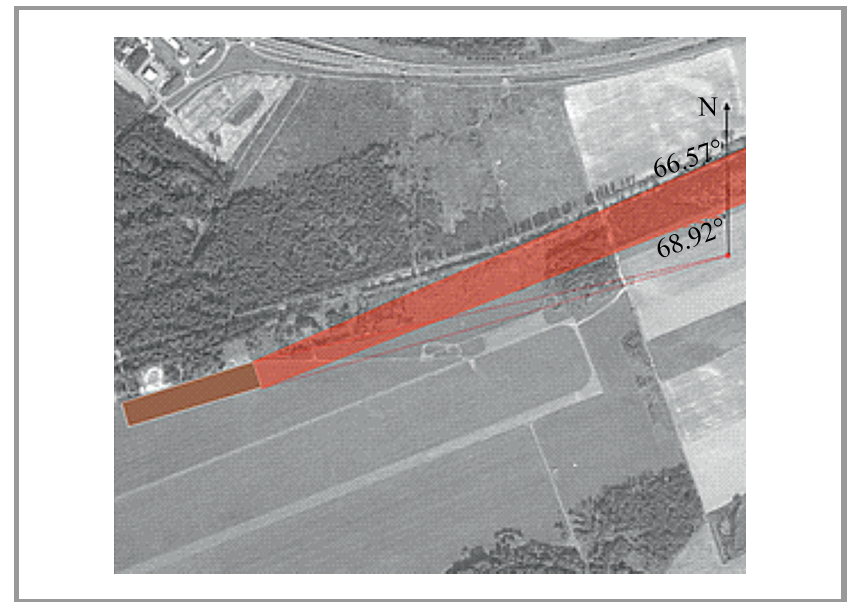

Fig. 17. Azimuth range within which horizontal reflections of the beams generated by DVOR/DME beacons from hotel buildings will occur.
Figure 17 illustrates, in the horizontal plane, the range of reflection of the signal beam from DVOR/DME beacons. In this case, the azimuth range of the reflected beacon beam is: $66.57-68.92^{\circ}$.

Finally, Fig. 18 presents the range of reflection of the beam generated by DVOR/DME beacons, from hotel buildings, in the vertical plane.

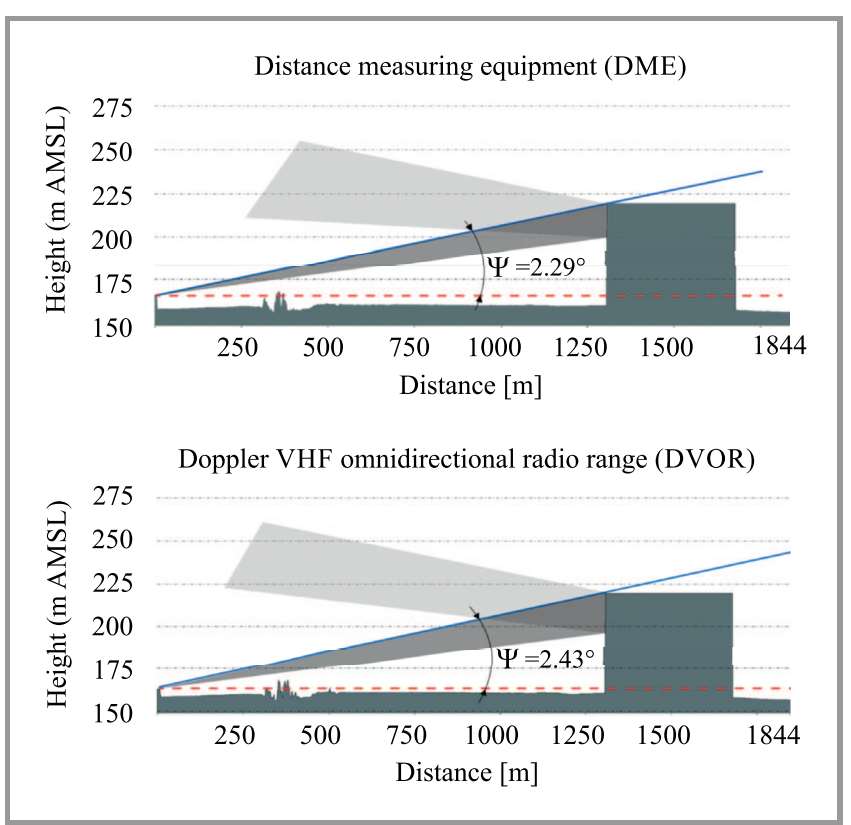

Fig. 18. Vertical azimuths below which beams of radio waves generated by DVOR/DME beacons are reflected by the building.

In this case, reflections of the radio waves generated by the beacons in the vertical plane, resulting from the presence of an obstacle in the form of a hotel building, will occur below the elevation angles of $2.29^{\circ}$ and $2.43^{\circ}$ for DME and DVOR, respectively. It means that low-flying aircraft may falsely determine the location of these beacons while traveling within such a range.

\subsection{Analysis of Scenarios in which the PSR Radar Receiver is Potentially Blocked}

Here, an analysis of the scenario in which the PSR radar circuit is potentially blocked upon receiving a strong signal reflected from nearby objects is performed with the worst propagation conditions taken into consideration and assuming that the beam radiated by the radar is fully reflected from these objects.

In this case, the radio path loss for the signal emitted by the radar and reflected from the object can be determined by the well-known formula for free-space basic transmission loss [16]:

$$
L_{b}=L_{b f}=32.4+20 \log f+20 \log d[\mathrm{~dB}],
$$

where $f$ is the frequency in $[\mathrm{MHz}]$ and $d$ is the distance in $[\mathrm{km}]$. 
Knowing the distance between the PSR radar and the nearby object, and being aware of the height of the radar antenna's electric center and the height of the object concerned, one may assess whether the radar receiver will be blocked by the reflection of the radiated beam.

Assuming the typical parameters of a PSR radar: $P_{p r}=32 \mathrm{~kW}=75.1 \mathrm{dBm}, f=2800 \mathrm{MHz}, G_{r}\left(\theta_{r}\right)=$ $33.0 \mathrm{dBi}$ and $L_{f o}=2 \mathrm{~dB}$, and using the distance from the radar antenna to the nearest building of approx. $693 \mathrm{~m}$, the loss of free-space path from the radar to the object is:

$$
\begin{array}{r}
L_{b f}=32.4+20 \log 2800+20 \log (2 \times 0.693) \\
=32.4+68.9+2.8=104.1 \mathrm{~dB} .
\end{array}
$$

Using the relative decrease in the gain of the receiving antenna, observed as the distance towards the object decreases (calculated based on the vertical characteristics of the PSR radar), for an incidence angle of $0^{\circ}$ in relation to the azimuth of maximum radiation $(3 \mathrm{~dB})$, the total gain of this antenna towards the considered building will be $33.0-3=30.0 \mathrm{~dB}$. With the assumed reflection coefficient of $R=1(0 \mathrm{~dB})$, the power of the signal received by the radar after reflection by the building is:

$$
P_{o}=75.1+30.0-104.1-2-0=-1.0 \mathrm{dBm} .
$$

According to [4], the average saturation level of an air traffic control (ATC) radar receiver is equal to $P_{b l}=13 \mathrm{dBm}$.

Thus, according to Eq. (2), the received signal power obtained above, after reflection from a (near) object $P_{o}$ is by $14 \mathrm{~dB}$ lower than the saturation power of the radar's receiver $P_{b l}$. In the scenario under consideration, the building will not block the operation of the PSR radar.

\section{Structure-related Restrictions Imposed by ICAO}

In order to reduce the probability of disturbances affecting the operation of ground-based air navigation equipment, caused by the close proximity of various building structures and radio shadowing, the International Civil Aviation Organization (ICAO), has defined the recommended minimum distances of radionavigation, radiolocation and air communication devices from nearby buildings [14]. The methodology relied upon for determining the boundaries of off-limits areas, i.e. the sizes of protection zones around groundbased air navigation equipment, is presented in Fig. 19, while the distances applicable to various types of such devices are shown in Table 6. It should be noted that apart from various types of structures, no other objects (mobile and stationary, permanent or temporary), terrain faults or vegetation of any kind should be present in the protected zones. If a structure needs to be positioned inside the protection zone, it is necessary to analyze its impact on the operation of each of the ground-based devices in operation.

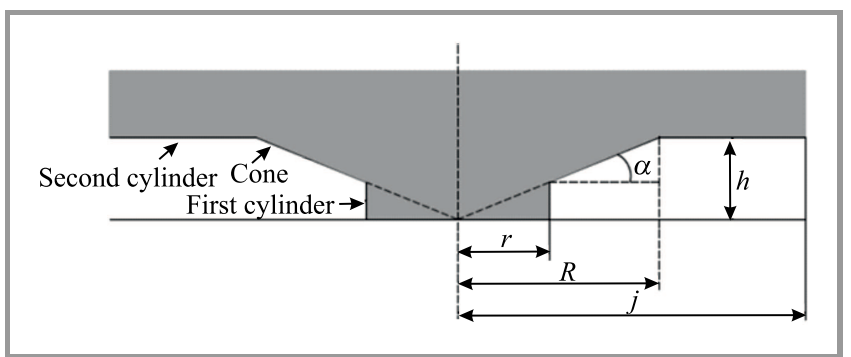

Fig. 19. Protection zones for aviation ground equipment [14].

Some general guidelines (but not having the form of formal standards) regarding the presence of buildings in the vicinity of DVOR/DME devices are also presented in [15].

ICAO recommends to designate protection zones around radiolocation devices and to define restricted areas in which the no structures should be present. These recommendations should be obeyed into practice. However, in some cases, when it is not possible to avoid the construction of such structures, it is necessary to identify those sectors of the airspace in which proper operation of radiolocation equipment may be affected.

\begin{tabular}{|c|c|c|c|c|c|c|}
\hline $\begin{array}{l}\text { Type of navigation or } \\
\text { surveillance facilities }\end{array}$ & $\begin{array}{l}\text { First cylinder } \\
\text { radius } r[\mathrm{~m}]\end{array}$ & $\mid \begin{array}{l}\text { Cone wall incli- } \\
\text { nation angle } a\left[^{\circ}\right]\end{array}$ & $\begin{array}{c}\text { Second cylinder } \\
\text { radius } R[\mathrm{~m}]\end{array}$ & $\mathrm{r} \begin{array}{c}\text { Second cylinder } \\
\text { radius } * j[\mathrm{~m}]\end{array}$ & $\begin{array}{c}\text { Second cylinder } \\
\text { height* } r[\mathrm{~m}]\end{array}$ & $\begin{array}{l}\text { Origin of cone and axis } \\
\text { of cylinders at ground level }\end{array}$ \\
\hline $\begin{array}{l}\text { Distance measuring } \\
\text { equipment DME N }\end{array}$ & 300 & 1.0 & 3000 & $n / a$ & $n / a$ & Base of antenna \\
\hline $\begin{array}{c}\text { Doppler VHF omni- } \\
\text { directional range DVOR }\end{array}$ & 600 & 1.0 & 3000 & 10000 & 52 & Centre of antenna systems \\
\hline $\begin{array}{l}\text { Primary surveillance } \\
\text { radar PSR }\end{array}$ & 500 & 0.25 & 15000 & $n / a$ & $n / a$ & Base of antenna \\
\hline $\begin{array}{c}\text { Secondary surveillance } \\
\text { radar SSR }\end{array}$ & 500 & 0.25 & 15000 & $n / a$ & $n / a$ & Base of antenna \\
\hline
\end{tabular}

Table 6

Data from Fig. 19 for selected radionavigation and radiolocation devices 


\section{Conclusions}

Data sourced from ground-based radiolocation and radionavigation systems are mainly used to identify aircraft, to determine their current location in the airspace and some of their flight-related parameters. The position of radionavigation devices on the ground is determined by the aircraft as well. It may be difficult or outright impossible to obtain such information when building structures and other man-made objects are located in the vicinity of air traffic control stations. In extreme cases, as a result of reflections of radio waves radiated by radar antennas, false positions of the aircraft may be presented. On the other hand, the radio shadowing phenomenon caused by the existence of terrain, artificial and natural obstacles, results in the operation of radiolocation devices being subjected to some spatial limitations.

The effects of such impact are presented based on the example of a fictitious building located in the vicinity of a runway of a closed airport in Poland. Those sectors of the airspace in which the positions of aircraft may be determined falsely or cannot be determined altogether due to radio shadowing have been established. The probability of blocking the radar receiver by radio waves it generates being reflected from a nearby object, was analyzed as well. In addition, those airspace sectors have been identified where it would be impossible for aircraft to identify the position of radio beacons due to the formation of dead zones (radio shadowing) caused by the presence of a building.

The methods relied upon for analyzing the impact of surroundings on the operation of radiolocation and radionavigation systems, as presented in this article, may facilitate forecasting unfavorable phenomena adversely affecting the operation of these systems (in a scenario in which buildings already exist in the vicinity of airports) and may also contribute to eliminating them at the design stage.

The calculation results presented indicate that the dimensions of their projection on the plane perpendicular to the direction of the radar devices were as small as possible (surface area and height).

In such scenario, the radio shadow created by the building will be minimized. In addition, the value of the angle at which false readouts indicating the position of flying objects or beacons will be minimized as well.

\section{References}

[1] M. J. Grzybkowski, "Environmental restrictions of the operation of air traffic radiolocation and radionavigation systems", KKRRiT, Warsaw, Poland, 2019, pp. 362-366 (DOI: 10.15199/59.2019.6.51).

[2] Recommendation ITU-R M.1462-1, "Characteristics of and protection criteria for radars operating in the radiolocation service in the frequency range 420-450 MHz", 2019 [Online]. Available: https://www.itu.int/rec/R-REC-M.1462/
[3] Recommendation ITU-R M.1463-3, "Characteristics of and protection criteria for radars operating in the radiodetermination service in the frequency band 1215-1400 MHz", 2015 [Online]. Available: https://www.itu.int/rec/R-REC-M.1463/

[4] Recommendation ITU-R M.1464-2, "Characteristics of nonmeteorological radiolocation radars, and characteristics and protection criteria for sharing studies for aeronautical radionavigation and radars in the radiodetermination service operating in the frequency band 2700-2900 MHz", 2015 [Online]. Available: https://www.itu.int/dms_pubrec/itu-r/rec/m/ R-REC-M.1464-2-201502-I!!PDF-E.pdf

[5] Recommendation ITU-R M.1638-1, "Characteristics of and protection criteria for sharing studies for radiolocation (except ground based meteorological radars) and aeronautical radionavigation radars operating in the frequency bands between 5250 and $5850 \mathrm{MHz}$, 2015 [Online]. Available: https://www.itu.int/rec/ R-REC-M.1638-1-201501-I/

[6] Recommendation ITU-R M.1461-2, "Procedures for determining the potential for interference between radars operating in the radiodetermination service and systems in other services", 2015 [Online]. Available: https://www.itu.int/rec/R-REC-M.1461-2-201801-I

[7] K. Frolic, "Developing buildings", 2020 [Online]. Available: https://www.pagerpower.com/news/ planning-issues-for-buildings-radar-interference/

[8] S. T. Shipley et al., "GIS tools for radar siting and analysis", 22nd Int. Conf. on Interactive Informat. Process. Systems for Meteorology, Oceanography, and Hydrology, Atlanta, GA, USA, 2006 [Online]. Available: https://ams.confex.com/ams/Annual2006/ techprogram/paper_104269.htm

[9] S. Shipley, D. Berkowitz, and R. M. Steadham, "Comparison of virtual globe technologies for depiction of radar beam propagation effects and impacts", AGU Fall Meeting Abstracts, San Francisco, CA, USA, 2007 [Online]. Available: https://ams.confex.com/ams/pdfpapers/135325.pdf

[10] G. Greving, "Numerical simulations of environmental distortions by scattering of objects for the radar - SSR and Flat Roofs, RCS and Wind-turbines", in Proc. of the 3rd European Radar Conf., Machester, UK, 2006, pp. 241-244 (DOI: 10.1109/EURAD.2006.280319).

[11] G. Greving, W.-D. Biermann, and R. Mundt, "On the advanced simulation of distortions for navigation, landing and radar systems - modern methods, cases and results", 13th IAIN World Congress, Stockholm, Sweden, 2009.

[12] G. Greving, W.-D. Biermann, and R. Mundt, "Dislocation aspects of wind-turbines within a wind-farm in some distance to primary radar, 18th Int. Radar Symp. IRS, Prague, Czech Republic, 2017 (DOI: 10.23919/IRS.2017.8008170).

[13] Recommendation ITU-R P.2040-1, "Effects of building materials and structures on radiowave propagation above about $100 \mathrm{MHz}$ ", 2015 [Online]. Available: https://www.itu.int/rec/ R-REC-P.2040-1-201507-I/

[14] ICAO, "European guidance material on managing building restricted areas, third edition", 2015 [Online]. Available: https://www.icao.int/EURNAT/ EUR\%20and\%20NAT\%20Documents/ EUR\%20Documents/ EUR\%20Documents/015\%20-\%20Building\%20Restricted\%20Areas

[15] ICAO, "Annex 10 to the Convention on International Civil Aviation, Aeronautical Telecommunications", Radio Navigation Aids, vol. 1, 2018 [Online]. Available: https://www.bazl.admin.ch/dam/bazl/en/ dokumente/Fachleute/Regulationen_und_Grundlagen/icao-annex/ icao_annex_10_aeronauticaltelecommunicationsvolumeiradionavigat.pdf.download.pdf/icao_annex_10_ aeronauticaltelecommunicationsvolumei-radionavigat.pdf

[16] Recommendation ITU-R P.525-4, "Calculation of free-space attenuation”, 2019 [Online]. Available: https://www.itu.int/rec/ R-REC-P.525/en 


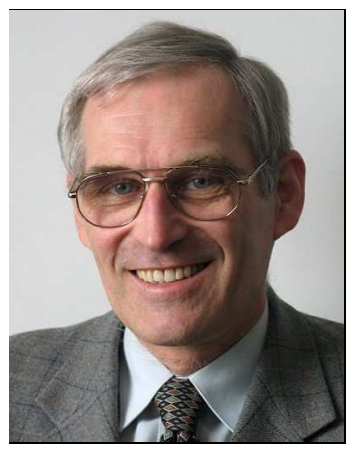

Maciej J. Grzybkowski (Ph.D.) is currently working at NIT's EMC Department. His research areas cover wireless telecommunication network technologies, $5 \mathrm{G}$ and beyond $5 \mathrm{G}$ wireless networks, planning and optimization of radio networks, radio frequency management and spectrum engineering, as well as wireless telecommunications, electromagnetic compatibility and radiowave propagation modeling. He is highly experienced in regulations concerning the electronic communications sector and in assessing national telecommunication legislation: drafting opinions on current and future regulations for the telecommunications markets. He took part in many research and commercial projects acting in the capacity of a Project Manager, researcher or reviewer. $\mathrm{He}$ is an author or co-author over 50 publications and more than 100 research and commercial reports of the NIT.

(iD) https://orcid.org/0000-0001-8591-8627

E-mail: m.grzybkowski@il-pib.pl

National Institute of Telecommunications

Szachowa 1

Warsaw, Poland

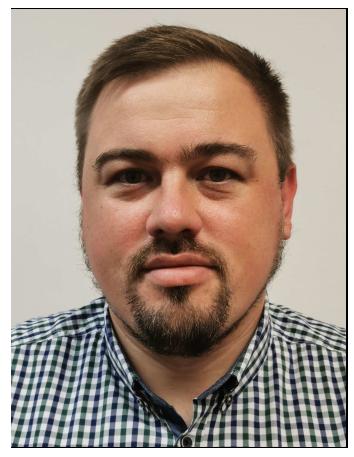

Daniel Niewiadomski (M.Sc.) currently holds the position of a Research Engineer at Spectrum Engineering and Management Section, National Institute of Telecommunications, Poland. His main research areas cover planning and optimization of radio networks, radio wave propagation modeling, broadcasting networks, EMF exposure simulations and Internet of Things wireless networks. He is an author or co-author over 100 research and commercial reports published by NIT. He represents Poland at the following international regulatory forums: ITU-R Study Groups, ITU-R WRC, CEPT Working Groups and Project Teams.

(iD) https://orcid.org/0000-0002-5576-6551

E-mail: d.niewiadomski@il-pib.pl

National Institute of Telecommunications

Szachowa 1

Warsaw, Poland

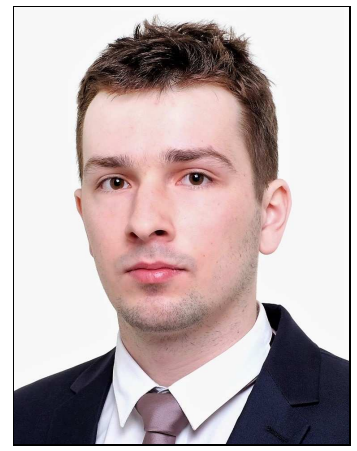

Marcin Mora received his M.Sc. degree in Telecommunications from Wrocław University of Technology in 2017. Since 2017, he has been working as an engineering specialist at the Spectrum Engineering and Management Section, National Institute of Telecommunications. His areas of research interest include: planning and optimization of radio networks, EMF simulations, 5G Networks, digital terrestrial television, mobile broadband networks, digital audio broadcasting and IoT. He represents Poland at the following international regulatory forums: CEPT Working Groups and Project Teams. He is a coauthor of 10 research and commercial reports published by NIT.

(iD) https://orcid.org/0000-0003-4427-6212

E-mail: m.mora@il-pib.pl

National Institute of Telecommunications

Szachowa 1

Warsaw, Poland 